\title{
Народовластный ресурс в развитии правосудия: отечественный опыт
}

\author{
Стус Н.В. \\ Российский государственный университет правосудия, Северо-Кавказский филиал, \\ Россия, 350002, г. Краснодар, ул. Им. Леваневского, дом 187/1 \\ E-mail: ninastus@mail.ru
}

\begin{abstract}
Аннотация. Статья 32 Конституции России предусматривает право граждан на участие в отправлении правосудия. В настоящее время в российском правосудии реализуются две формы такого участия - суд присяжных и арбитражные заседатели. Подсудность дел суду присяжных значительно сокращена. Дел с участием арбитражных заседателей рассматривается ничтожно малое количество. В связи с этим авторами исследован вопрос о возможности использования других моделей участия народа в отправлении правосудия: введение суда народных (судебных) заседателей; расширение возможности рассмотрения дел с участием арбитражных заседателей; возрождение института общественных защитников и общественных обвинителей; реформирование суда присяжных.
\end{abstract}

Ключевые слова: народные заседатели, арбитражные заседатели, общественный защитник, суд присяжных.

Для цитирования: Стус Н.В. 2021. Народовластный ресурс в развитии правосудия: отечественный опыт. NOMOTHETIKA: Философия. Социология. Право, 46 (2): 376-384. DOI 10.52575/2712-746X2021-46-2-376-384

\section{People's power resources in the development of justice: domestic experience}

\author{
Nina V. Stus \\ Russian State University of Justice, North-Caucasian Branch, \\ 187/1 Levanevsky St, Krasnodar, 350002, Russian Federation \\ E-mail: ninastus@mail.ru
}

\begin{abstract}
Article 32 of the Russian Constitution provides for the right of citizens to participate in the administration of justice. Currently, the Russian justice system implements two forms of such participation - trial by jury and arbitration assessors. The jurisdiction of cases to the jury is significantly reduced. A negligible number of cases involving arbitration assessors are considered. In this regard, the article examines the possibility of using other models of people's participation in the administration of justice: the introduction of the court of people's (judicial) assessors; the expansion of the possibility of considering cases with the participation of arbitration assessors; the revival of the institution of public defenders and public prosecutors; the reform of the jury court. The article presents the results of the analysis of doctrinal and legal sources, taking into account the ongoing judicial reform. It is reasonable that in the future, the people's power resource will be fully involved in the administration of justice, and the changes will be of an essential nature, aimed at further constitutionalization of the judiciary as a sphere of state activity.
\end{abstract}

Keywords: people's assessors, arbitration assessors, public defender, jury trial.

For citation: Stus N.V. 2021. People's power resources in the development of justice: domestic experience. NOMOTHETIKA: Philosophy. Sociology. Law series, 46 (2): 376-384 (in Russian). DOI 10.52575/2712746X-2021-46-2-376-384 


\section{Введение}

В соответствии с положениями ч. 1 и 2 ст. 3 Конституции Российской Федерации носителем суверенитета и единственным источником власти в нашей стране является многонациональный народ, а согласно ст. 33 граждане Российской Федерации имеют право участвовать в отправлении правосудия. В настоящее время единственной хорошо известной формой участия представителей народа в осуществлении правосудия в судах общей юрисдикции является институт присяжных заседателей. Однако Конституция России не ограничивает возможность участия народа в «отправлении правосудия только рассмотрением уголовных дел с участием коллегии присяжных заседателей, что позволяет законодателю расширить сферы привлечения к осуществлению судопроизводства на любом его этапе присяжных (народных) заседателей» [Belkin, 2009, p. 196], а также заседателей-специалистов, какими были арбитражные заседатели. При этом такая форма участия народных представителей может иметь место как в уголовном, так и в гражданском, административном судопроизводстве.

По мнению ряда исследователей, участие граждан в отправлении правосудия является межотраслевым принципом судопроизводства. «Участие граждан в отправлении правосудия имеет особую конституционно-правовую значимость, определяет качественные характеристики судебной власти, является основополагающим принципом отношений между демократическим государством и гражданами, представляет собой форму реализации суверенитета народа, позволяет ему непосредственно осуществлять свою власть, выполняет функцию общественного контроля над правосудием» [Лакоба, 2018, с. 40].

Принцип участия граждан в осуществлении правосудия и две формы такого участия (в качестве присяжных и арбитражных заседателей) закреплены в ст. 8 Федерального конституционного закона от 31 декабря 1996 года № 1-ФКЗ «О судебной системе Российской Федерации» ${ }^{1}$. Данное положение нашло развитие в отраслевых процессуальных законах, подробно регламентирующих основания, условия и порядок рассмотрения некоторых категорий дел с участием непрофессиональных судей. Вместе с тем ни один отраслевой процессуальный кодекс не закрепляет положение об участии граждан в осуществлении правосудия в качестве принципа соответствующего вида судопроизводства. Уголовно-процессуальный кодекс РФ подробно регулирует порядок рассмотрения дел судом с участием присяжных заседателей в специальном XII разделе, упоминая этот состав суда в главе о принципах лишь применительно к свободе оценки доказательств ${ }^{2}$. Арбитражный процессуальный кодекс РФ содержит положение о рассмотрении дел в арбитражном суде первой инстанции в ст. 17 «Единоличное и коллегиальное рассмотрение дел» и ст. 19 «Привлечение к рассмотрению дел арбитражных заседателей», которые находятся не в главе 1, содержащей принципы арбитражного судопроизводства, а в главе 2 , посвященной составу суда ${ }^{3}$. С учетом конституционного характера участия народного элемента в рассмотрении и разрешении дел судом как формы непосредственного народовластия данное положение имеет все основания для признания межотраслевым принципом судопроизводства. Но для полного уяснения вопроса о необходимости привлечения представителей народа к отправлению правосудия обратимся к отечественному опыту реализации данного принципа, включая и правозащитный аспект [Мархгейм, Новикова, 2008, с. 38-40].

${ }^{1}$ Федеральный конституционный закон от 31.12.1996 № 1-ФКЗ «О судебной системе Российской Федерации» (ред. от 08.12.2020) // С3 РФ. 1997. № 1. Ст. 1; 2020. № 50 (часть І). Ст. 8029.

2 Уголовно-процессуальный кодекс Российской Федерации от 18.12.2001 № 174-ФЗ (ред. от 05.04.2021, с изм. от 13.04.2021) // С3 РФ. 2001. № 52 (ч. І). Ст. 4921; 2021. № 15 (Часть I). Ст. 2434.

${ }^{3}$ Арбитражный процессуальный кодекс Российской Федерации от 24.07.2002 № 95-Ф3

(ред. от 08.12.2020) // СЗ РФ. 2002. № 30. Ст. 3012; 2020. № 50 (часть III). Ст. 8073. 


\section{Генезис народного представительства при отправлении правосудия}

Общество и его представители всегда присутствовали в отправлении правосудия. Правосудие изначально предстает как компонент общества и лишь в дальнейшем, пройдя в своем развитии библейский, общинный и другие этапы, становится компонентом государства [Гегель, 1990].

В правосудии России представительство народа при отправлении правосудия имеет свою длительную историю. В связи с этим необходимо вспомнить суд Одрин в Новгороде. В суде Одрин, помимо председателя, присутствовали десять заседателей: каждый конец города (а их было всего пять) избирал по одному именитому гражданину [Памятники русского права, 1953]. Кроме этого, каждая из тяжущихся сторон назначала в суд Одрин одного посредника, называемого приставом, который имел право принимать участие в судебном разбирательстве. Таким образом, этот суд состоял из двенадцати членов и председателя. Эти заседатели, присутствующие на суде Одрин, назывались докладчиками, так как присутствовали при докладе или слушании дел, однако имели право решающего голоса, а княжеский тиун был только выразителем их мнения [Куницын, 1843].

В последующем представительство народа осуществлялось посредством участия судных мужей и целовальников. Хотя они и не были судьями в полном смысле, но являлись «оберегателями правды на суде», свидетелями, удостоверяющими своей подписью правильность и достоверность судебного протокола. При этом не могли выражать свое мнение о виновности или невиновности подсудимого.

Безусловно, наиболее значительным этапом участия выборных представителей в отправлении правосудия мы связываем с проведением судебной реформы 1864 года - введением суда присяжных. После 1917 года суд присяжных перестал действовать, сменив свое наименование на суд с участием народных заседателей. Принятый 30 ноября 1918 года Декрет ВЦИК «О народном суде Российской Социалистической Федеративной Советской Республики (положение)» в ст. 1 провозглашал, что «в пределах РСФСР учреждается единый народный суд в составе: 1) одного постоянного судьи; 2) двух или шести очередных судей народных заседателей ${ }^{1}$. В ст. 7 установлено: «Народный суд действует в составе постоянного народного судьи и шести очередных народных заседателей при рассмотрении уголовных дел: о посягательствах на человеческую жизнь, причинение тяжких ран или увечье, изнасилование, разбой подделка денежных знаков и документов, взяточничество и спекуляция монопольными и нормированными продуктами потребления.

Декрет в ЦИК от 21 декабря 1920 года вводит в действие Положение о народном суде РСФСР и вновь подтверждает положение о шести народных заседателях ${ }^{2}$. Принятый в 1922 году Уголовно-процессуальный кодекс РСФСР закрепил положение о шести народных заседателях и в ч. 2 ст. 26 установил, что «преступления, предусмотренные ст. ст. 142150, 160-162, 166-171, 183 и 197 Уголовного кодекса, рассматриваются исключительно в составе народного судьи и шести народных заседателей» ${ }^{3}$. Однако Уголовно-процессуальный кодекс РСФСР 1923 года уже не предусматривал рассмотрение уголовных дел в расширенной коллегии народных заседателей при рассмотрении некоторых преступлений.

Институт народных заседателей в гражданском судопроизводстве просуществовал до 1 февраля 2003 года ${ }^{4}$, а в уголовном - до 1 января 2004 года ${ }^{5}$. Однако упразднению института

${ }^{1}$ СУ РСФСР. 1918. Ст. 889. № 85: 812.

${ }^{2}$ СУ РСФСР. 1920. Ст. 407. № 83: 342.

${ }^{3}$ Народный комиссариат юстиции. Собрание узаконений и распоряжений рабочего и крестьянского правительства. 1922, 20-21: 207.

${ }^{4}$ Федеральный закон от 14.11.2002 № 137-Ф3 «О введении в действие Гражданского процессуального кодекса Российской Федерации» (ред. от 01.05.2019) // СЗ РФ. 2002. № 46. Ст. 4531; 2019. № 18. Ст. 2224.

${ }_{5}^{5}$ Федеральный закон от 18.12.2001 № 177-Ф3 «О введении в действие Уголовно-процессуального кодекса Российской Федерации» (ред. от 23.06.2016) // СЗ РФ. 2001. № 52 (1 ч.). Ст. 4924. 
народных заседателей в гражданском процессе предшествовало введение института арбитражных заседателей. На первый взгляд вызывает недоумение введение института, который на тот момент потерял свою значимость как форма участия представителей народа в отправлении правосудия. Но законодатель наполнил содержание этого института новым смыслом, сформулировав в законе иные требования к арбитражным заседателям. Так, в силу п. 1 ст. 2 Федерального закона от 30 мая 2001 года № 70-Ф3 «Об арбитражных заседателях арбитражных судов субъектов РФ» к арбитражным заседателям предъявляются следующие требования: достижение возраста 25 лет, но не старше 70 лет; безупречная репутация; наличие высшего образования; наличие не менее 5 лет стажа работы в сфере экономической, финансовой, юридической, управленческой или предпринимательской деятельности ${ }^{1}$.

«Именно качественный состав арбитражных заседателей являлся важнейшей характеристикой, отличавшей их от прежних народных заседателей.

То есть, теперь народный-арбитражный заседатель - это судья - специалист в определенной сфере общественно-экономических отношений» [Зайков, 2019, с. 55].

Очень ярко этот новый принцип отбора представителей общества для участия в отправлении правосудия охарактеризовал в интернет-конференции Председатель Высшего Арбитражного Суда РФ В.Ф. Яковлев: «Штатный судья - это юрист, и не более. А ведь для того чтобы рассмотреть сложнейший предпринимательский спор, например, в сфере банковской и кредитной деятельности, расчетной деятельности, с применением, скажем, категории ценных бумаг, надо досконально знать эту сферу отношений, с которыми в данном случае соприкасаешься. Не всегда юрист способен разобраться в тонкостях этого дела. Арбитражные заседатели - это не представители народа, не люди с улицы, а специалисты, которые должны знать соответствующее предпринимательское дело» ${ }^{2}$.

К сожалению, в настоящее время число дел, рассматриваемых с участием арбитражных заседателей, невелико. В научной среде этот вопрос тщательно анализируется. По мнению Д.Е. Зайкова, низкий уровень «вовлеченности арбитражных заседателей в рассмотрение дел обусловлен несколькими причинами: внутренними противоречиями законодательства, отсутствием четкого определения категорий дел, которые могут рассматриваться с участием арбитражных заседателей, нежеланием судей арбитражных судов рассматривать дела с участием арбитражных заседателей. По его мнению, изменение ст. 19 Арбитражного процессуального кодекса РФ в части предоставления сторонам права на рассмотрение их дела с участием арбитражных заседателей, с исключением дискреции судей по этому вопросу позволит вдохнуть новую жизнь в институт арбитражных заседателей и обеспечить участие граждан в осуществлении правосудия в арбитражных судах» [Зайков, 2019, с. 55].

Аналогичную точку зрения высказывает Р.М. Джавахян, анализируя статистические данные о ежегодном снижении количества дел, рассмотренных с участием арбитражных заседателей. «При этом необходима кардинальная модернизация этого института, которую необходимо начать с изменения порядка формирования и утверждения списков арбитражных заседателей, приостановления и прекращения их полномочий судами, поскольку указанный порядок ставит арбитражных заседателей в зависимость от судов, препятствует формированию самостоятельной позиции по рассматриваемым делам» [Джавахян, 2017, с. 45].

Рассматривая вопросы отечественного опыта в реализации конституционного принципа участия народа в отправлении правосудия, необходимо остановиться на переходном

1 Федеральный закон от 30.05.2001 № 70-Ф3 «Об арбитражных заседателях арбитражных судов субъектов РФ»// СЗ РФ. 2001. № 23. Ст. 2288.

${ }^{2}$ Яковлев В.Ф. Председатель Высшего Арбитражного Суда РФ. Интернет-конференция «Новые задачи арбитражной системы России» от 18.12.2002 // http://viperson.ru/articles /yakovlev-novyezadachi-arbitrazhnoy-sistemy-rossii (дата обращения 11.02.2021). 
периоде, когда в ряде субъектов Российской Федерации уже действовал суд присяжных, но продолжал существовать институт народных заседателей.

Так, с 1 ноября 1993 года суд присяжных был учрежден в пяти субъектах Российской Федерации и еще в четырех субъектах с 1 января 1994 года. С возрождением суда присяжных на территории девяти субъектов Российской Федерации уголовное судопроизводство России изменило не только форму, но и содержание. Впервые в уголовно-процессуальный закон были включены принципы состязательности, презумпции невиновности, право не свидетельствовать против себя, исключение из судебного разбирательства доказательств, полученных с нарушением закона.

Две существовавшие на тот момент модели участия граждан в рассмотрении уголовных дел принципиальным образом отличались: присяжные заседатели принимали решение самостоятельно в совещательной комнате, а народные заседатели вместе с профессиональным судьей. Однако введение института присяжных заседателей существенно повлияло на содержание уголовного судопроизводства в целом, заменив процесс розыскной на состязательный, наполнив новым смыслом роли государственного обвинителя и защитника.

Указанный период времени со всей очевидностью свидетельствует о возможности одновременного существования различных по своей сути форм участия граждан в отправлении правосудия в зависимости от сложности дела, уровня суда, его рассматривающего, волеизъявления обвиняемого.

\section{Современный период народного представительства при отправлении правосудия}

В настоящее время уголовные дела с участием присяжных заседателей, подсудные суду присяжных, подразделены на несколько групп в зависимости от того, в совершении каких преступлений предъявлено обвинение. Дела, отнесенные к подсудности суда присяжных, немногочисленны, и сложность таких дел может быть различной в зависимости от фактических обстоятельств, количественного состава обвиняемых и множественности эпизодов.

При обсуждении вопроса о расширении полномочий суда присяжных традиционно звучит мнение о громоздкости этой процедуры, трудностях при формировании коллегии присяжных, длительности процесса.

Представляется, что разрешение этого вопроса возможно с возвращением к незаслуженно отвергнутой форме участия граждан в отправлении правосудия - участию народных заседателей, которых можно назвать «судебными» заседателями. Это изменение в законе послужило бы как фактором укрепления и развития демократических основ правосудия, так и укрепило бы доверие общества к суду.

Следует также заметить, что в настоящее время не все категории лиц, которым предъявлено обвинение в совершении преступлений, подсудных суду присяжных, имеют право на рассмотрение дела таким судом. Такого права лишены несовершеннолетние обвиняемые, так как им не может быть назначено наказание в виде смертной казни и пожизненного лишения свободы. Данное положение было предметом рассмотрения Конституционного Суда РФ, и в Постановлении от 20 мая 2014 года № 16-П было указано, что «в системе действующего законодательства у лиц, совершивших преступление в возрасте до восемнадцати лет, отсутствует право на суд присяжных» ${ }^{1}$. В такой ситуации возможность рассмотрения дел с участием народных заседателей может быть альтернативой суду присяжных, поскольку дела в отношении несовершеннолетних представляют особую сложность, исходя

${ }^{1}$ Постановление Конституционного Суда РФ от 20.05.2014 № 16-П «По делу о проверке конституционности пункта 1 части третьей статьи 31 Уголовно-процессуального кодекса Российской Федерации в связи с жалобой гражданина В.А. Филимонова» // СЗ РФ. 2014. № 22. Ст. 2920. 
из необходимости оценки всей совокупности доказательств по делу с обязательной оценкой личности обвиняемого, условий совершения преступления.

В этой связи также необходимо обратить внимание на возможность привлечения граждан к участию в рассмотрении дел в отношении несовершеннолетних в различном качестве, начиная от законного представителя, специалиста, психолога, эксперта.

Обсуждая вопрос о необходимости возвращения института народных заседателей в уголовное судопроизводство, остановимся на вопросе избрания и продлении меры пресечения единолично судьей. Ходатайство об избрании меры пресечения в виде содержания под стражей рассматривается, как правило, дежурным судьей с участием дежурного адвоката. Следователь представляет минимум материалов в подтверждение своего ходатайства, за исключением разве только случаев задержания подозреваемого на месте совершения преступления. Результаты оперативно-розыскных мероприятий не приобщены к материалам дела. При таких обстоятельствах суд в лице единственного председательствующего судьи должен принять решение, которое в дальнейшем во многом может определить ход расследования, а иногда судьбу и саму жизнь подозреваемого. При этом необходимо учитывать нежелание судьи вступать в конфронтацию со следствием и прокуратурой, опасение коррупционных обвинений и других неблагоприятных последствий.

Помимо того, что мера пресечения избирается единолично судьей, в апелляционном порядке жалобы на постановление об избрании меры пресечения также в соответствии с действующим уголовно-процессуальным законом рассматриваются судьей единолично, в то время как все гражданские дела рассматриваются в апелляционном порядке коллегиально. Отдаленное по времени кассационное рассмотрение жалобы на постановление об избрании меры пресечения в большинстве случаев не всегда является своевременным и эффективным. При этом также следует иметь в виду, что следователь вправе сам отменить или изменить избранную судом меру пресечения.

В настоящее время в наибольшей степени участие граждан в отправлении правосудия реализуется посредством суда присяжных. Однако полный отказ от иных, кроме суда присяжных, форм участия народа при отправлении правосудия вряд ли оправдан. Пассивность народных заседателей не является неизменным спутником правосудия с их участием. Активность народных заседателей может быть повышена соответствующей организацией процесса, процедурой формирования корпуса народных заседателей из числа социально активных граждан, а также работой по правовому просвещению, нацеленной на повышение уровня правосознания граждан, осознание ими общественной важности роли народных судей при осуществлении правосудия.

Не вдаваясь в процессуальные особенности рассмотрения дел с участием присяжных заседателей, все же отметим, что наибольшую сложность представляет составление вопросного листа, в котором перед присяжными ставятся не только три основных вопроса о доказанности события преступления, совершения его именно подсудимым и его виновности, но и так называемые альтернативные вопросы по различным версиям обстоятельств совершения преступления. Нередко это приводит к тому, что присяжные заседатели, не будучи профессиональными юристами, путаются в вариантах возможных ответов и правовых последствиях. Содержание вопросного листа должно быть простым и лаконичным, понятным для присяжных.

Внесение изменений в действующий уголовно-процессуальный закон в этой части позволит избежать досадных ошибок и отмены приговоров, постановленных на основании противоречивых вердиктов присяжных заседателей.

Необходимо признать, что, несмотря на наличие определенных трудностей и внутренних противоречий, суд присяжных является на сегодняшний день единственной реальной действующей формой непосредственного участия граждан в отправлении правосудия, что соответствует процессам глобализации в современном праве [Макогон, 2007, 2012]. 
В связи с этим инициативы по расширению подсудности дел такому суду являются своевременными, и крайне необходима их скорейшая реализация.

Обосновывая возвращение института народных заседателей в российское правосудие, отметим, что такая модель участия граждан в отправлении правосудия является традиционной, понятной и достаточно эффективной. При решении вопросов в совещательной комнате профессиональным судьей и представителями народа достижим некий баланс, который позволит с наибольшей степенью вероятности принять не только законное, обоснованное, но и справедливое решение.

Участие народных заседателей в рассмотрении административных споров значительно укрепит позицию суда и в некотором смысле защитит от возможности ощущения силы «административного ресурса». Одновременно гражданин в споре с властью может рассчитывать на полную объективность состава суда, поскольку в состав его входят такие же граждане.

«Незаслуженно предана забвению такая форма участия граждан в осуществлении правосудия, как участие в судебном разбирательстве общественных обвинителей и общественных защитников. В ст. 250 старого УПК РФ было предусмотрено участие этих представителей общественности (представители общественного объединения или профессионального союза. Они были наделены достаточно большим объемом прав при рассмотрении уголовных дел: представлять доказательства, принимать участие в их исследовании, заявлять отводы и ходатайства, участвовать в прениях.

После вступления в силу нового Уголовно-процессуального кодекса институт общественных защитников и обвинителей претерпел столь существенные изменения, что можно говорить о фактическом упразднении этого института» [Очередько, 2018, с. 243]. Так, теперь, в соответствии с ч. 2 ст. 49 Уголовно-процессуального кодекса РФ, по усмотрению суда к участию в деле может быть допущен наряду с адвокатом защитник из числа родственников обвиняемого или иных лиц, не являющихся при этом адвокатами.

Представляется, что возвращение в уголовное судопроизводство утраченного института общественных обвинителей и защитников не только будет новым шагом в реализации конституционного принципа участия граждан в осуществлении правосудия, но также послужит серьезным фактором в реализации права на защиту обвиняемого, обеспечения прав потерпевших, повышения доверия к суду.

Рассматривая вопрос о допуске общественного защитника и общественного обвинителя к участию в уголовном судопроизводстве, необходимо обратить внимание на момент, когда вышеназванные представители общественности могут быть допущены к участию в деле.

Общеизвестно, что при отсутствии у подозреваемого, обвиняемого, подсудимого денежных средств, а подчас по совету следователя, дознавателя, к участию в деле допускают дежурного адвоката. Возможность участия общественного защитника в уголовном судопроизводстве с момента допуска адвоката значительно бы повлияла на аспект охраны достоинства личности [Butko et al., 2017], укрепило бы право подозреваемого, обвиняемого на защиту, поскольку такого защитника он мог бы выбрать по собственному усмотрению, с учетом степени доверия указанному лицу, не будучи скован финансовым положением.

Безусловно, такая новация требует серьезной правовой регламентации, поскольку необходимо четко определить, кто может быть допущен к участию в деле в качестве общественного защитника и с каким объемом полномочий. Но эффективность этого института позволит избежать судебных ошибок с момента избрания меры пресечения и до принятия окончательного решения по делу. Институт общественных обвинителей может стать серьезным и действенным индикатором отношения общества к совершенным преступлениям. А при рассмотрении дела судом с участием присяжных заседателей позиция общественного обвинителя может играть серьезную роль в оценке доказательств, представляемых государственным обвинителем, которого нередко присяжные заседатели воспринимают как должностное лицо, которое действуют по приказу. 
Несмотря на довольно длительную историю суда присяжных, в современной России не утихают споры по поводу его необходимости. Результатом стало введение суда присяжных в районных городских и гарнизонных судах.

Представляется, что, несмотря на определенные сложности формирования коллегии присяжных в небольших городах, суд присяжных именно в такой местности, действуя от лица общества, не только осуждает или оправдывает подсудимого, но и выполняет очень важную воспитательную роль. Преступление получает публичную огласку и, соответственно, подсудимый подвергается осуждению не только со стороны государства (признание лица виновным и назначение наказания профессиональным судьей), но и общества.

\section{Заключение}

В ст.ст. 3, 10 и 11 Конституции РФ устанавливают принципы народовластия и разделения властей. Представляется, что в различные периоды осуществления судебной реформы в современной России отсутствовал системный подход к реализации принципа народовластия в сфере судебной власти. Но судебная реформа продолжается, и прослеживаемый вектор реформирования дает основания надеяться, что народовластный ресурс будет задействован при отправлении правосудия в полной мере, а изменения будут носить сущностный характер, направленный на дальнейшую конституционализацию судебной власти как сферы государственной деятельности.

\section{Список литературы}

1. Гегель. 1990. Философия права. М., Мысль, 53 с.

2. Джавахян Р.М. 2017. Совершенствование форм участия граждан в осуществлении правосудия как механизм конституционного преобразования судебной власти. Российский юридический журнал, 2: 45-54.

3. Зайков Д.Е. 2019. Институт арбитражных заседателей: современное состояние и перспективы. Российская юстиция, 7: 55-57. СПб, 33 с.

4. Куницын А.П. 1843. Историческое изображение древнего судопроизводства в России.

5. Лакоба А.Д. 2018. О некоторых аспектах судебной защиты прав человека и права граждан на участие в отправлении правосудия. Адвокатская практика, 4: 40-42.

6. Макогон Б.В. 2007. Общая характеристика процессов глобализации в правовой сфере. История государства и права, 3: 2-4.

7. Макогон Б.В. 2012. Способы интернационализационного национального права в условиях глобализации. Общество и право, 2 (39): 36-41.

8. Мархгейм М.В., Новикова А.Е. 2008. Правозащитные приоритеты в воззрениях отечественных представителей либеральной и консервативной научных школ. История государства и права, 6: 38-40.

9. Очередько В.П. 2018. Развитие форм участия граждан в отправлении правосудия в России. Ленинградский юридический журнал, 3(53): 243-252.

10. Памятники русского права. Вып. 2. 1953. М., Госюриздат, 218 с.

11. Belkin A. 2009. Disputed merits and undoubted shortcomings of the jury. Russian law: theory and practice, 2: 196-203.

12. Butko, L.V., Markhgeym, M.V., Novikova, A.E., Pozharova, L.A., Tonkov, E.E. 2017. Personal Dignity in the European Legal Culture. Journal of History Culture and Art Research, Vol. 6, 4: 296-303.

\section{References}

1. Gegel'. 1990. Filosofiya prava [Philosophy of Law]. M.: Mysl', seriya «Filosofskoe nasledie», 53. (In Russian)

2. Dzhavahyan R.M. 2017. Sovershenstvovanie form uchastiya grazhdan v osushchestvlenii pravosudiya kak mekhanizm konstitucionnogo preobrazovaniya sudebnoj vlasti [Improving the forms of 
citizens ' participation in the administration of justice as a mechanism for the constitutional transformation of the judiciary]. Rossijskij yuridicheskij zhurnal [Russian Law Journal], 2: 45-54. (In Russian)

3. Zajkov D.E. 2019. Institut arbitrazhnyh zasedatelej: sovremennoe sostoyanie i perspektivy [Institute of Arbitration Assessors: current state and prospects]. Rossijskaya yusticiya [Russian Justice], 7: 55-57. (In Russian)

4. Kunicyn A.P. 1843. Istoricheskoe izobrazhenie drevnego sudoproizvodstva $v$ Rossii [Historical depiction of ancient judicial proceedings in Russia]. SPb, 33. (In Russian)

5. Lakoba A.D. 2018. O nekotoryh aspektah sudebnoj zashchity prav cheloveka i prava grazhdan na uchastie $\mathrm{v}$ otpravlenii pravosudiya [On some aspects of judicial protection of human rights and the right of citizens to participate in the administration of justice]. Advokatskaya praktika [Law Practice], 4: 40-42. (In Russian)

6. Makogon B.V. 2007. Obshchaya harakteristika processov globalizacii v pravovoj sfere [General characteristics of the processes of globalization in the legal sphere]. Istoriya gosudarstva i prava [History of State and Law], 3: 2-4. (In Russian)

7. Makogon B.V. 2012. Sposoby internacionalizacionnogo nacional'nogo prava v usloviyah globalizacii [Methods of internationalization of national law in the context of globalization]. Obshchestvo i pravo [Society and Law], 2 (39): 36-41. (In Russian)

8. Marhgejm M.V., Novikova A.E. 2008. Pravozashchitnye prioritety v vozzreniyah otechestvennyh predstavitelej liberal'noj i konservativnoj nauchnyh shkol [Human rights priorities in the views of Russian representatives of liberal and conservative scientific schools]. Istoriya gosudarstva i prava [History of State and Law], 6: 38-40. (In Russian)

9. Ochered'ko V.P. 2018. Razvitie form uchastiya grazhdan $v$ otpravlenii pravosudiya $v$ Rossii [Development of forms of citizen participation in the administration of justice in Russia]. Leningradskij yuridicheskij zhurnal [Leningrad Law Journal], 3(53): 243-252. (In Russian)

10. Pamyatniki russkogo prava [Monuments of Russian Law]. 1953. M.: Vyp. 2, 218. (In Russian)

11. Belkin A. 2009. Disputed merits and undoubted shortcomings of the jury. Russian law: theory and practice, 2: 196-203.

12. Butko, L.V., Markhgeym, M.V., Novikova, A.E., Pozharova, L.A., Tonkov, E.E. 2017. Personal Dignity in the European Legal Culture. Journal of History Culture and Art Research, T. 6, 4: 296-303

\section{ИНФОРМАЦИЯ ОБ АВТОРЕ}

Стус Нина Владимировна, доктор юридических наук, профессор кафедры общетеоретических правовых дисциплин Северо-Кавказского филиала Федерального государственного бюджетного образовательного учреждения высшего образования «Российский государственный университет правосудия», г. Краснодар, Россия

\section{INFORMATION ABOUT THE AUTHOR}

Nina V. Stus, Doctor of Law, Professor of the Department of General Theoretical Legal Disciplines of the North Caucasus Branch of the Federal State Budgetary Educational Institution of Higher Education «Russian State University of Justice», Krasnodar, Russia 